\title{
Implementation Intentions: Strategic Automatization of Goal Striving
}

\author{
Paschal Sheeran, Thomas L. Webb, and Peter M. Gollwitzer
}

Several theories that have been used to understand the self-regulation of behavior in pursuit of health goals, including the Theory of Planned Behavior (TPB; Ajzen, 1991), Protection Motivation Theory (PMT; Rogers, 1983), the Prototype/Willingness Model (PWM; Gibbons, Gerrard, Blanton \& Russell, 1998), Control Theory (Carver \& Scheier, 1982), and Social Cognitive Theory (Bandura, 1997), consider the formation of a goa intention as the key act of willing in promoting goal attainment. Goal intentions can be defined as the instructions that people give themselves to perform particular behaviors or to achieve certain desired outcomes (Triandis, 1980) and characteristically are measured by items of the form "I intend to achieve $X$ !" Forming a goal intention serves to end deliberation about behaviors or outcomes and indicates the standard of performance that one has set oneself, one's commitment to the performance, and the amount of time and effort that will be expended during action (Ajzen, 1991; Gollwitzer, 1990; Webb \& Sheeran, 2005a).

Although key health behavior theories construe goal intentions as the most important predictor of behavior and goal achievement, at least 3 lines of research indicate that there is often a substantial "gap" between intention and action. First, correlational studies indicate that much of the variance in behavior is not explained by measures of goal intentions. For instance, Sheeran (2002) meta-analyzed 10 previous meta-analyses of correlational research and found that intentions accounted for only $28 \%$ of the variance in behavior, on average, across 422 studies. Second, Fife-Schaw, Sheeran and Norman (in press) used statistical simulations to estimate the impact of maximally effective TPB interventions on the likelihood of performing 30 behaviors. Findings indicated that even if participants all had the maximum possible attitude, subjective norm, and perceived behavioral control scores, and thus the highest possible intention scores that could be 
generated by a TPB intervention, the predicted probability was that $26 \%$ of the sample would still fail to translate their intentions into action. Finally, a meta-analysis of the experimental evidence indicates that intention change does not guarantee behavio change. Webb and Sheeran (in press) reviewed 47 intervention studies that generated statistically significant differences in intention scores between treatment versus control participants and subsequently followed up behavior. Findings indicated that the difference in behavior that accrued from successful intention-change interventions was only $d_{+}=0.36$ (equivalent to $R^{2}=0.03$ ). This is a modest effect size according to Cohen's (1992) criteria.

Evidence indicates that discrepancies between intentions and action arise because people find it difficult to translate their "good" intentions into action, that is, people often fail to do the things that they say they want to do, or fail to avoid doing things that they do not want to do (Orbell \& Sheeran, 1998; Sheeran, 2002). A review of health behavior (e.g., exercise, condom use, cancer screening) indicated that people were successful in enacting their goal intentions only $53 \%$ of the time (Sheeran, 2002). Thus, it is accurate to say that the "gap" between intention and action is substantial.

Gollwitzer and Sheeran (in press) pointed out that "good" intentions do not guarantee goal attainment because committing oneself to the pursuit of a particular goal (i.e., forming a respective goal intention) is only the starting point en route to goal completion. The person still must deal effectively with a series of self-regulatory problems in order to attain desired outcomes. Two particular problems that appear to plague strivings for health goals are failures to initiate action ("get started") or to shield an ongoing goal pursuit from unwanted influences ("stay on track") (Gollwitzer \& Sheeran, in press; Sheeran, Milne, Webb \& Gollwitzer, 2005). Clearly, it would benefit tates of attainmen of health goals if there were some means of managing these self-regulatory problems, and thereby "bridging" the intention-behavior gap.

Gollwitzer (1993, 1996, 1999; Gollwitzer, Bayer \& McCulloch, 2005; Gollwitzer \& Schaal, 1998; Gollwitzer \& Sheeran, in press) proposed the strategy of forming implementation intentions as a simple and effective tool for dealing with self-regulatory problems in goal striving. In the sections that follow, we define the concept of implementation intentions and describe how this type of planning promotes intention realization. Next, we review evidence concerning the effectiveness of implementation intention formation in promoting health behaviors and assess evidence about explanatory mechanisms. The final sections examine factors that determine the strength of implementation intention effects and offer suggestions for future research.

\section{THE NATURE AND OPERATION OF IMPLEMENTATION INTENTIONS}

Implementation intentions are if-then plans that connect good opportunities to act with responses that will be effective in accomplishing one's goals. Whereas goal intention specify what one wants to do/achieve (i.e., "I intend to perform behavior $W$ in order to obtain outcome $X$ !"), implementation intentions specify the behavior that one will perform in the service of goal achievement and the situational context in which one will enact it (i.e., "If situation $Y$ occurs, then I will initiate goal-directed behavior $Z$ !")
Implementation intentions are subordinate to goal intentions because, whereas a goal intention specifies what one will do, an implementation intention spells out the when, where, and how of what one will do.

To form an implementation intention, the person must first identify a response that is instrumental for goal attainment and, second, anticipate a suitable occasion to initiate that response. For example, the person might specify the behavior "order the salad for lunch" and specify a suitable opportunity as "when the waiter takes my order at the café tomorrow" in order to enact the goal intention to eat healthily. Implementation intention formation is the mental act of linking an anticipated critical situation with an effective goal-directed response. An association is formed between mental representations of specified opportunities (situations) and means of attaining goals (cognitive or behavioral responses) in an act of will.

The mental links created by implementation intentions are expected to facilitate goa attainment on the basis of psychological processes that relate both to the anticipated situation (the if-component of the plan) and the intended behavior (the then-component of the plan). Because forming implementation intentions implies the selection of a critical future situation (i.e., a suitable opportunity), it is assumed that the mental representation of this situation becomes highly activated, and hence more accessible (Gollwitzer, 1999). This heightened accessibility should benefit information processing in relation to the specified situation. In particular, people should be in a good position to identify and take notice of the critical cue when they encounter it later.

\section{Processes Related to the If-component}

Several studies have tested the idea that the mental representation of the situation specified in the if-part of the implementation intention becomes highly accessible by examining how well participants holding implementation intentions detected and attended to the critical situation compared to participants who had only formed goal intentions (Gollwitzer, Bayer, Steller \& Bargh, 2002; Webb \& Sheeran, 2004). Evidence that implementation intentions improve detection of the critical situation was obtained in a study using the embedded figures test (Gottschaldt, 1926), where smaller a-figures were hidden within larger b-figures (Gollwitzer et al,, 2002). Enhanced detection of the hidden a-figures was observed when participants had specified the a-figure in the if-part of an implementation intention (i.e., had made plans on how to create a traffic sign from the a-figure). Equivalent findings were obtained in a study that used a classic illusion from the psychology of language (Webb \& Sheeran, 2004, Study 1). Participants who formed if-then plans in relation to the critical letter $F$ showed superior letter detection compared to a variety of control conditions, even though detection was extremely difficult. Two additional experiments by Webb and Sheeran (2004) indicated that forming an if-then plan engendered faster and more accurate responses to critical cues without compromising responses to irrelevant or ambiguous cues.

In a study using a dichotic-listening paradigm, Gollwitzer et al. (2002) observed that words describing the anticipated critical situation attracted and focused attention among implementation intention participants. Participants who formed if-then plans seemed to find it difficult to overlook information about the critical situation presented in the 
unattended channel; the consequence was that their shadowing performance for the attended material decreased relative to goal intention participants. This finding implies that opportunities to act that are specified in implementation intentions will not easily escape people's attention, even when people are busy with other ongoing tasks.

\section{Processes Related to the Then-component}

The mental act of linking a critical situation and an intended goal-directed behavior in the form of an if-then plan parallels the formation of associations between situations and actions during the development of habits. Habits and if-plans both are characterized by strong links between (mental representations of) particular cues and responses. Moreover, in the same way that the operation of habits is automatic (Bargh, 1994) in the sense that action control becomes immediate, efficient, and needless of conscious intent (Aarts \& Dijksterhuis, 2000a, b; Sheeran, Aarts et al., 2005; Verplanken \& Aarts, 1999; Wood Quinn \& Kashy, 2002), there is evidence that action control by implementation intentions also exhibits these features of automaticity.

Gollwitzer and Brandstätter (1997, Study 3) showed the immediacy of action initiation by implementation intentions in a study where participants were asked to form plans that specified viable opportunities for presenting counterarguments to a series of racist remarks made by a confederate. Participants who formed implementation intentions initiated the relevant counterargument more quickly (i.e., closer to the intended time) than did participants who had only formed goal intentions to counter-argue (see Orbell \& Sheeran, 2000; Webb \& Sheeran, 2004 for similar findings). The efficiency of action initiation was tested by Brandstätter, Lengfelder and Gollwitzer (2001, Studies 3 and 4) using a Go/No-Go-task. Participants formed the goal intention to press a button as quickly as possible if numbers appeared on the computer screen, but not if letters appeared. Participants in the implementation intention condition also planned to press the button particularly fast if the number 3 was presented. This Go/No-Go task was then embedded as a secondary task in a dual task paradigm. Findings showed that implementation intention participants showed a substantial increase in speed of responding to the number 3 compared to the control group, regardless of whether the primary task that had to be performed simultaneously was easy or difficult. These findings support the idea that implementation intention effects are efficient; the operation of if-then plans cannot require much in the way of cognitive resources because they facilitated performance even when two tasks were undertaken at the same time.

The redundancy of conscious intent for implementation intention effects has also been demonstrated in several experiments. Bayer, Moskowitz and Gollwitzer (2002) tested whether implementation intentions lead to action initiation without conscious intent once the critical situation is encountered. In these experiments, the critical situation was presented subliminally and its impact on preparing to perform (Study 1) or performing (Study 2) respective goal-directed behaviors was assessed. For instance, participants in Study 2 were asked to classify a series of geometrical figures (e.g., circles, eclipses, triangles, squares) into rounded versus angular objects using left versus right button press responses. All participants formed the goal intention to classify the figures as quickly and accurately as possible. Implementation intention participants also made the following plan: "And if I see a triangle, then I press the respective button particularly fast!" Participants worked on a set of 240 figures, presented in succession on a computer screen. Some of the figures were preceded by the subliminal presentation of the critical figure (i.e., a triangle), whereas others were preceded by a control prime (i.e., the $\%$ symbol). Findings indicated that participants in the implementation intention condition had faster classification responses for angular figures when the triangle instead of the \% symbol was presented as a subliminal prime; no such speed-up effect was observed among goal intention participants.

In another study, Sheeran, Webb and Gollwitzer (2005, Study 2) gave participants the conscious goal to solve a series of puzzles as accurately as possible. One half of the participants also formed an implementation intention in relation to another dimension of performance, namely, to answer the puzzles as quickly as possible. This implementation intention manipulation was then crossed with a situational priming manipulation that was designed to activate the goal of responding quickly. Speed and accuracy of responses to the puzzles was measured subsequently. Even though participants indicated no awareness that the puzzle task activated a task-relevant goal during debriefing (participants all reported that their only goal was to solve the puzzles accurately), the results showed that the puzzles were solved fastest when participants were primed with the goal of responding quickly and had formed an if-then plan. These findings indicate that people's conscious intent is not required for implementation intentions to affect performancepeople need not be aware that they have encountered the critical cue specified in their plan (Bayer et al., 2002) or even be aware of the goal driving their behavior (Sheeran, Webb et al., 2005).

Both implementation intentions and habits engender swift, effortless responses that do not require conscious instigation or guidance. In addition, these effects of if-then plans and habits both are underpinned by strong associations between cues and responses. However, there is an important difference between implementation intentions and habits that accrues from the fact that the respective cue-response links have different origins. In the case of habits, frequent and consistent execution of a response in the presence of a particular stimulus leads to the development of the relevant associations. In the case of implementation intentions, the same linkage can be fashioned in situ by an act of will. Implementation intention effects thus represent an important sub-type of automaticity that differs from the automaticity in habits (Gollwitzer \& Schaal, 1998; Sheeran, Webb et al., 2005). Implementation intentions allow people to choose, consciously and in advance, what goal-directed responses will be elicited automatically, and what situational cues will elicit them. By making an if-then plan, people decide to delegate control of their behavior to pre-selected situational features with the express purpose of reaching their goals. This is what is meant by the idea that forming an implementation intention entails strategic automatization of goal striving.

\section{Implementation Intentions and Other Conceptions of Planning}

Strategic automaticity distinguishes implementation intentions from other conceptions of planning. For instance, seminal research by Leventhal showed that giving participants action plans (e.g., instructions on how to stop smoking) enhanced the behavioral impact 
of fear appeals in relation to both smoking (Leventhal, Singer \& Jones, 1965) and tetanus (Leventhal, Watts \& Pagano, 1967). Similarly, the Health Action Process Approach (HAPA; Schwarzer, 1992) points to the importance of planning in helping people to translate intentions into action, and empirical studies have shown that plan formation improved prediction of health behaviors after goal intentions have been taken into account (e.g., Abraham et al., 1999; Jones, Abraham, Harris, Schulz \& Chrispin, 2001). In the field of safer sex, Sheeran, Abraham and Orbell (1999) proposed that engaging in preparatory behaviors such as buying and carrying condoms and discussing their use with a sexual partner were prerequisites for condom use. Bryan, Fisher and Fisher (2002) tested this idea and found that performance of these preparatory behaviors mediated the relationship between intentions to use condoms and condom use. Action plans and preparatory behaviors are similar to implementation intentions in that these concepts all suggest that people benefit from working out a method of acting in some detail before getting started on goal striving (i.e., from having a plan). However, the literature on action plans and preparatory behaviors does not specify what components must be included in the plan (i.e., what details need to be spelled out), what the structure of the plan should be, or what are the mechanisms by which planning promotes goal achievement. Each of these features of plans is specified by implementation intention theory, on the other hand (Gollwitzer, 1993, 1996, 1999; Gollwitzer \& Schaal, 1998; Gollwitzer \& Sheeran, in press).

The components that should be specified in an implementation intention are a good opportunity to act (the if-component) and an instrumental goal-directed response (the then-component). Furthermore, the plan should have a conditional if-then structure ("If situation $Y$ occurs, then I will initiate goal-directed behavior $Z$ !"). This structure is important to ensure that the if-component of the plan becomes highly activated, and a strong link is forged between the if-component and then-component of the plan. Heightened accessibility of critical cues and strong cue-response links, in turn, are responsible for enhanced detection of situational cues and automation of responding; the processes that account for implementation intention effects on performance and goal attainment.

A study by Oettingen, Hönig and Gollwitzer (2000, Study 3) provided evidence that specifying the opportunity and goal-directed response in the format of an if-then plan has greater impact on performance compared to merely specifying the respective opportunity and goal-directed response. As part of the procedure, participants were provided with diskettes containing four concentration tasks and were asked to perform these tasks on their computers each Wednesday morning for the next four weeks. Participants in the control condition were asked to indicate what time they would perform the task by responding to the statement "I will perform as many arithmetic tasks as possible each Wednesday at ___elf-chosen time before noon)." Participants in the implementation intention condition, on the other hand, indicated their chosen time by responding to the statement "If it is Wednesday at ___ (self-chosen time before noon), then I will perform as many arithmetic tasks as possible!" The program on the diskette recorded the time that participants started to work on the task from the clock on participants' computers.

Even though the implementation intention and control instructions involved the same components (i.e., specifying the performance of a particular behavior at a particular time on a particular day), the conditional structure of the implementation intention had an important effect on whether participants performed the task at the time they intended to perform it. The mean deviation from the intended start time was five times greater in the control condition ( 8 hours) compared to the implementation intention condition (1.5 hours). These findings suggest that respective opportunities and goal-directed responses should be specified in an if-then format to engender strategic automatization of goal striving (see also Jaudas \& Gollwitzer, 2004, cited in Gollwitzer et al., in press).

\section{IMPLEMENTATION INTENTIONS \\ AND ATTAINMENT OF HEALTH GOALS}

Accumulated evidence indicates that forming an implementation intention increases the likelihood of performing behaviors in the service of health goals compared to the formation of a goal intention on its own. Gollwitzer and Sheeran (in press) reviewed 23 studies of health goals as part of a larger meta-analysis of implementation intention effects. Table 6.1 describes the samples, behaviors, and effect sizes in these studies. The sample-weighted average effect size obtained from the 23 studies was $d_{+}=0.59$ (95\% $C I=0.52$ to 0.67 ) which was similar to the effect size obtained for the 94 studies inciuded in the overall meta-analysis $\left(d_{+}=0.65\right)$. According to Cohen's (1992) power primer, $d_{+}=0.20$ should be considered a "small" effect size, $d_{+}=0.50$ is a "medium" effect size, whereas $d_{+}=0.80$ is a "large" effect size. Thus, the effect of implementation intention formation on the attainment of health goals is of medium-to-large magnitude.

\section{Types of Health Behavior}

Several distinctions are worth making in relation to the reviewed health behaviors that serve to clarify the impact of implementation intention formation on attainment of health goals. The first concerns whether obtaining a wanted response or controlling an unwanted response was at issue (Gollwitzer et al., 2005). Findings indicate that implementation intentions were effective in promoting wanted responses such as exercise participation (Milne, Orbell \& Sheeran, 2002; Prestwich, Lawton \& Conner, 2003; Sniehotta, Scholz \& Schwarzer, 2002b), healthy eating (Armitage, 2004; Verplanken \& Faes, 1999) and various types of cancer screening (e.g., Orbell, Hodgkins \& Sheeran, 1997; Sheeran \& Orbell, 2000; Steadman \& Quine, 2004). Although there were fewer studies concerned with controlling unwanted responses, implementation intention formation also proved beneficial in reducing consumption of snack foods (Orbell \& Sheeran, 1999; Sheeran \& Milne, 2003), regulating alcohol-related cognitions and behavior (Gollwitzer, Sheeran, Trötschel \& Webb, 2005, Study 2; Murgraff, White \& Phillips, 1996), and resisting smoking (Stephens \& Conner, 1999; see also Higgins \& Conner, 2004).

A second distinction concerns the frequency of performance of respective health behaviors. Wood and colleagues showed that behaviors that are performed frequently in stable situational contexts are controlled more by habits than by goal intentions (Ouellette \& Wood, 1998; Wood, Kashy \& Kenny, 2002). Given the parallels between habits and implementation intentions described earlier, this might suggest that if-then plans are 
Table 6.1 Effects of implementation intention formation on the attainment of health goals

\begin{tabular}{|c|c|c|c|c|}
\hline Author(s) & Sample & Goal & $N$ & $d$ \\
\hline \multicolumn{5}{|l|}{ Wanted behaviours } \\
\hline Armitage (2004) & Company employees & Eating a low-fat diet & 126 & 0.30 \\
\hline $\begin{array}{l}\text { Lippke \& Ziegelmann } \\
\quad(2002)\end{array}$ & $\begin{array}{l}\text { Myocardial infarction } \\
\text { patients }\end{array}$ & Exercise & 88 & 0.18 \\
\hline $\begin{array}{l}\text { Milne, Orbell \& } \\
\text { Sheeran (2002) }\end{array}$ & University students & Exercise & 248 & 1.25 \\
\hline Milne \& Sheeran (2002a) & University students & Testicular self-examination & 432 & 0.43 \\
\hline $\begin{array}{l}\text { Orbell, Hodgkins \& } \\
\text { Sheeran (1997) }\end{array}$ & $\begin{array}{l}\text { University Students } \\
\text { and Staff }\end{array}$ & Breast self-examination & 155 & 1.22 \\
\hline Orbell \& Sheeran (2000) & $\begin{array}{l}\text { Joint replacement } \\
\text { patients }\end{array}$ & $\begin{array}{l}\text { Recovery of functional } \\
\text { activities }\end{array}$ & 64 & 0.70 \\
\hline $\begin{array}{l}\text { Prestwich, Lawton \& } \\
\text { Conner (2003b) }\end{array}$ & University students & Exercise & 58 & 0.68 \\
\hline $\begin{array}{l}\text { Sheeran \& Orbell } \\
\text { (1999) Study } 1\end{array}$ & University students & Vitamin supplement use & 78 & 0.35 \\
\hline $\begin{array}{l}\text { Sheeran \& Orbell } \\
\text { (1999) Study } 2\end{array}$ & University students & Vitamin supplement use & 37 & 0.59 \\
\hline Sheeran \& Orbell (2000) & Patients attending GP & Cervical cancer screening & 104 & 0.58 \\
\hline $\begin{array}{l}\text { Sheeran \& Silverman } \\
\quad(2003)\end{array}$ & University employees & $\begin{array}{l}\text { Workplace safety training } \\
\text { attendance }\end{array}$ & 271 & 0.52 \\
\hline $\begin{array}{l}\text { Sniehotta, Scholz \& } \\
\text { Schwarzer (2002a) }\end{array}$ & $\begin{array}{l}\text { Myocardial infarction } \\
\text { patients }\end{array}$ & $\begin{array}{l}\text { Cardiac rehabilitation } \\
\text { training }\end{array}$ & 74 & 0.61 \\
\hline $\begin{array}{l}\text { Sniehotta, Scholz \& } \\
\text { Schwarzer }(2002 b)\end{array}$ & $\begin{array}{l}\text { Myocardial infarction } \\
\text { patients }\end{array}$ & Physical activity & 65 & 0.70 \\
\hline Steadman \& Quine $(2000)$ & University students & Vitamin supplement use & 174 & 0.32 \\
\hline Steadman \& Quine (2004) & University students & Testicular self-examination & 75 & 0.54 \\
\hline Verplanken \& Faes (1999) & University students & Healthy eating & 102 & 0.47 \\
\hline \multicolumn{5}{|l|}{ Unwanted behaviours } \\
\hline $\begin{array}{r}\text { Orbell \& Sheeran } \\
\text { (1999) Study } 3\end{array}$ & University students & $\begin{array}{l}\text { Reduce snack food } \\
\text { consumption }\end{array}$ & 111 & 0.61 \\
\hline $\begin{array}{r}\text { Orbell \& Sheeran } \\
\text { (1999) Study } 4\end{array}$ & University students & $\begin{array}{l}\text { Reduce snack food } \\
\text { consumption }\end{array}$ & 93 & 0.45 \\
\hline Sheeran \& Milne (2003) & University students & $\begin{array}{l}\text { Reduce snack food } \\
\text { consumption }\end{array}$ & 129 & 0.49 \\
\hline $\begin{array}{l}\text { Murgraff, White \& } \\
\text { Phillips (1996) }\end{array}$ & University students & Reduce binge drinking & 102 & 0.68 \\
\hline $\begin{array}{l}\text { Gollwitzer, Sheeran et al. } \\
\text { (2005) Study } 3\end{array}$ & University students & $\begin{array}{l}\text { Reduced accessibility } \\
\text { of drinking }\end{array}$ & 72 & 0.49 \\
\hline $\begin{array}{l}\text { Gollwitzer, Sheeran et al. } \\
\text { (2005) Study } 6\end{array}$ & University students & $\begin{array}{l}\text { Avoiding errors in } \\
\text { driving simulator }\end{array}$ & 72 & 0.49 \\
\hline $\begin{array}{l}\text { Stephens \& Conner } \\
\text { (1999) }\end{array}$ & School children & Resist taking up smoking & 124 & 0.37 \\
\hline
\end{tabular}

mainly effective in promoting frequently performed behaviors. Implementation intention formation proved beneficial in promoting frequently performed behaviors (i.e., behaviors that are performed daily such as vitamin supplement use; e.g., Sheeran \& Orbell, 1999; Steadman \& Quine, 2000). Health behaviors that generally are performed with moderate frequency (i.e., monthly) such as breast and testicular self-examinations also benefited from implementation intention formation (Milne \& Sheeran, 2002a; Orbell et al., 1997), as did behaviors that generally are performed infrequently (annually or biannually) including cervical cancer screening (Sheeran \& Orbell, 2000) and workplace health and safety training (Sheeran \& Silverman, 2003). These findings are consistent with the idea that implementation intentions involve a different sub-type of automaticity compared to habits. The automaticity in implementation intentions is strategic and does not appear to be affected by frequency of performance; unlike habits whose operation demands that respective responses were executed repeatedly and consistently in the presence of the same stimuli in the past.

A third important distinction concerns whether the initiation or maintenance of a health behavior was at issue. Orbell and Sheeran's (2000) study of patients undergoing joint replacement surgery provides a good example of behavioral initiation. This is because in the immediate wake of surgery, patients must try to resume activities of daily living (e.g., bathe, make a cup of tea) from scratch. Findings indicated that even though there were no differences between the groups on relevant clinical variables (type of surgery, pain, etc.), participants who formed implementation intentions initiated 18 out of 32 activities sooner than did participants who did not form if-then plans. On average, the implementation intention group was functionally active 2.5 weeks earlier than the control group. Several other studies that either examined behaviors that were novel for participants (e.g., testicular self-examinations; Milne \& Sheeran, 2002a; Sheeran \& Orbell, 1999) or explicitly asked participants to alter their usual behavior patterns (e.g., halve one's consumption of a favorite snack food; Sheeran \& Milne, 2003) also speak to the utility of implementation intentions in promoting initiation of behavior.

It is important to note that when initiation of behavior is easy, positive goal intentions may satisfactorily promote performance, and forming an if-then plan may not confer any additional benefit. For instance, Sheeran and Orbell (1999, Study 1) found that participants who formed implementation intentions to take a vitamin pill each day fared no better in their pill intake over 10 days compared to participants who only formed goal intentions. A recent meta-analysis supports the idea that interventions that increase participants' goal intentions sometimes lead to initiation of behavior (Webb \& Sheeran, in press). However, the findings also indicate that the impact of goal intention-change interventions declines rapidly over time (see also McCaul, Glasgow \& O'Neill, 1992; Sheeran \& Orbell, 1998), which suggests that appropriate motivation is not generally enough to maintain behavioral performance. In contrast, implementation intention effects are not characterized by such temporal decline. Sheeran and Orbell (1999) found that differences in vitamin pill intake between implementation intention and goal intention participants emerged after 3 weeks (but not 10 days). Moreover, Sheeran and Silverman (2003) showed that if-then planning increased attendance at health and safety training regardless of whether the training session specified by participants was in the near (0-3 weeks) or distant future (5-9 weeks). Perhaps the best evidence that if-then plans engender maintenance of behavior change comes from a longitudinal study of 
testicular self-examination (Milne \& Sheeran, 2002a: see also Sheeran, Milne et al., 2005). Findings showed that implementation intention formation not only enhanced the rate of initiation of behavior over 1 month (rates were $44 \%$ versus $22 \%$ for implementation intention and control groups, respectively), but also enhanced the rate of behavioral maintenance over 1 year. Participants who formed implementation intentions were more than twice as likely to report routine performance of testicular self-examination each month during the preceding 12 months compared to controls (37\% versus 15\%). In sum, implementation intentions appear to be effective in promoting health behaviors no matter whether relevant performances are wanted or unwanted, frequent or infrequent, or novel, familiar, or persistent.

\section{Types of Self-regulatory Problem}

It is also the case that different self-regulatory problems are likely to characterize the reviewed health behaviors. Two key problems that can undermine behavioral performance and goal attainment are failing to get started with goal striving and failing to keep goal striving on track (Gollwitzer and Sheeran, in press). People may fail to start striving for health goals for at least three reasons. First, people might forget to act. Einstein, McDaniel, Williford, Pagan and Dismukes (2003) showed that when participants are preoccupied with other tasks, they generally fail to initiate intended behaviors, even when the time interval to performance is as short as 15 seconds. Retrospective reports from participants who did not act on their positive intentions to engage in breast selfexaminations or exercise (Milne et al., 2002; Orbell et al., 1997) also confirm that remembering to act is a big problem in getting started. Second, even when they remember to act, people may fail to seize good opportunities to initiate goal striving. For example, participants in Sheeran and Silverman's (2003) study had to act within particular windows of opportunity in order to attend health and safety training (training courses were only available at particular dates, times, and locations). Failing to grasp available opportunities meant missing the course that semester. Similarly, people can miss out on opportune moments to move towards their goal because they do not know how to act at the critical juncture (e.g., how to reduce their cravings for snack food; e.g., Orbell \& Sheeran, 1999).

A third problem in getting started with goal striving is overcoming initial reluctance to act. Decisions to perform health behaviors such as monthly testicular self-examinations often are based on the longer-term benefits of the action (e.g., the exam will prevent the development of serious cancer). However, short-term affective costs (e.g., embarrassment, discomfort) that perhaps were not anticipated at the time of deciding may loom large at the moment of acting, and lead to non-performance of the behavior. Initial reluctance to act can be a serious impediment to the achievement of health goals; for example, when the goal intention to halve one's consumption of a favorite snack (Sheeran \& Milne, 2003 ) is faced with the reality of Italian ice cream, people might be inclined to deliberate anew about the desirability and feasibility of their original decision, and revise their goal intention in line with short-term considerations. However, the findings presented in Table 6.1 indicate that implementation intention formation helps people to overcome these various self-regulatory problems in initiating goal striving. Participants who furnished their goal intentions with if-then plans were unlikely to forget to act (e.g., Milne et al., 2002; Orbell et al., 1997; Sheeran \& Orbell, 1999), and generally did not miss viable opportunities for acting (e.g., Sheeran \& Orbell, 2000; Sheeran \& Silverman, 2003) or become swayed by short-term costs at the moment of action (e.g., Milne \& Sheeran, 2002a; Sheeran \& Milne, 2003).

Forming implementation intentions can also help people deal effectively with the second major self-regulatory problem in goal striving, staying on track. Shielding ongoing activities from unwanted influences is important because most health behaviors require repeated and persistent performance in order to prevent illness and enhance longevity (e.g., vigorous exercise, good diet).

The reviewed health behaviors are likely to involve at least two factors that could derail ongoing goal pursuit, namely, adverse contextual influences and unwanted habitual responses (Gollwitzer \& Sheeran, in press). Social pressure from other people to perform health-risk behaviors is one such adverse contextual influence. Behaviors such as smoking or binge drinking generally are performed in social contexts, and peers are likely to provide a good deal of verbal or non-verbal feedback about appropriate ways of behaving in that setting. When situational norms favor risk-taking, young people need to deal effectively with such unwanted social influences in order to resist smoking initiation and avoid binge drinking. Forming if-then plans about how to manage these interactions and withstand social pressure clearly benefited people who intended not to engage in these behaviors (e.g., Murgraff et al., 1996; Higgins \& Conner, 2004; Stephens \&. Conner, 1999). For instance, Murgraff et al. (1996) asked participants to specify how they would respond if someone invited them to have another drink (e.g., "No thanks. I have to get up early tomorrow!"). Findings showed that student participants who formed this implementation intention significantly reduced their alcohol consumption over a two-week period compared to control participants who did not form a plan.

Whereas people may be aware of social pressure from others about how they should behave, there is another adverse contextual influence that could derail an ongoing goal pursuit of which people are unaware, namely, situational priming of behavior. Accumulated research indicates that activating stereotypes, traits, or goals outside of awareness (i.e., priming) has predictable effects on behavior (reviews by Bargh \& Ferguson, 2000; Dijksterhuis \& Bargh, 2001; Gollwitzer \& Bargh, in press). Evidence that priming affects health-related behavior came from an experiment by Sheeran, Aarts, et al. (2005, Experiment 1). Participants who were habitual or non-habitual drinkers answered to a series of questions designed to activate the concept of socializing or they answered questions about a neutral concept. Subsequently, participants completed a lexical decision task where they responded to the verb "drinking" among other words. Findings indicated that activating the concept of socializing increased habitual drinkers' readiness to drink, as was shown by increased accessibility of the action concept drinking. Moreover, these effects occurred outside of awareness (automatically); participants reported no insight into the operation of the goal or its effects on behavioral readiness during debriefing.

Behavior priming effects cannot easily be controlled by goal intentions because people are not aware of the concepts (traits, goals) activated by the situation or of the effects of concept activation on their behavior. However, spelling out how the focal goal will be pursued in the format of an if-then plan can be used to shield the ongoing goal pursuit from the effects of antagonistic behavior primes (Gollwitzer, Sheeran, Trötschel \& Webb, 2005). For instance, Gollwitzer et al. (2005, Study 3) replicated key features of 
the socializing-drinking experiment presented above. Participants were exposed to the socializing prime or neutral prime and undertook a lexical decision task as before. Prior to both of these tasks, however, participants formed an implementation is before. Prior to they would suppress thoughts related to drinking or a neutral behavior (snacking) as part again showed the irrelevant-plan participants, finding again showed that the socializing prime increased the accessibility of drinking behavior Participants who formed relevant if-then plans, on the other hand, were protected against the impact of priming. Activation of the concept of socializing made no difference to these participants' readiness to drink. Thus, implementation intentions can be used to shield ongoing goal pursuit from adverse contementation intentions can be used to influences originate pursuit from adverse contextual influences, no matter whether these influences originate within, or outside of, people's awareness.

Unwanted habitual responding is the second problem that could derail ongoing pursuit of the health goals reviewed in Table 6.1. When relevant situational stimuli remain constant and the behavior is executed frequently the the habitual mode stimuli remain is more powerful than is the incitual mode of action control from several studies that ine intentional mode (e.g., Ouellette \& Wood, 1998). Findings habits consistently that used frequency of past behavior to index habit bear out this idea; habits consistently offered better prediction of subsequent behavior compared to intentions (e.g., Orbell et al., 1997; Sheeran \& Milne, 2003; Sheeran \& Orbell, 2000). However, implementation intention formation appears to provide an effective defense against habitual responding. For instance, although previous delay behavior was the most important determinant of attendance for important determinant of attendance for cervical cancer screening among the sample as a whole (Sheeran \& Orbell, 2000), forming an if-then plan enhanced prediction of account. In fact after delay behavior and motivational variables had been taken into account. In fact, having a plan significantly attenuated the relationship between previous delay and subsequent attendance among participants who planned ( $r$ s were -0.29 and -0.70 , for the implementation intention and control groups, respectively).

A more compelling test is afforded by examining the impact of counter-intentional habits on subsequent performance. When respective goal intentions involve changing established behavior pattern (e. situational contexts prion of a favorite snack food), behaviors and make it especially activate representations of previously performed (2004) found make it especially difficult to maintain goal striving. However, Sheeran (2004) found that even though snack consumption during the previous week was the best helped motivated individuals to reduce consumption were obtained by Verplaten anceptually equivalent findings were obtained by Verplanken and Faes (1999) using a response-frequency measure of
dietary habits.

These findings for health behaviors parallel the results of social psychological research on implementation intentions and the control of unwanted habits. Implementation intentions proved effective in promoting goal attainment in the fabe of Implementation of antagonistic habits including overlearned responding (We face of a wide variety 2005) the Simon effect (Brïwer Bayer \& responding (Webb, Sheeran \& Luszczynska, Gallo, McCulloch \& Gollwitzer, Bayer \& Gollwitzer, 2002), spider phobia (SchweigerGallo, McCulloch \& Gollwitzer, 2002), and automatic stereotype activation (Gollwitzer, Achtziger, Schaal \& Hammelbeck, 2002; see Gollwitzer, Jaudas, Parks \& Sheeran, in press, for a review). Overall, the presented findings indicate that forming implementation intentions is an effective means of handling self-regulatory problems in initiating and maintaining goal striving, and can bridge the intention-behavior gap.

\section{MECHANISMS OF IMPLEMENTATION INTENTION EFFECTS}

Because implementation intention inductions ask participants to specify a behavior that will be instrumental for goal attainment and a good opportunity to initiate that behavior, it is possible that plan formation might enhance people's intentions or self-efficacy in relation to the focal goal. If this analysis is accurate, then implementation intention effects should be explained by motivational factors. However, at least two lines of research contradict this position. First, studies that measured goal intentions or selfefficacy both before and after respective implementation intention inductions found no evidence that plan formation increased scores on these variables in either withinparticipants analyses (differences within the intervention group over time) or betweenparticipants analyses (differences between the intervention and control group at either time point) (e.g., Milne et al., 2002; Orbell et al., 1997; Sheeran \& Orbell, 1999; Sheeran, Webb et al., 2005). Second, implementation intention formation enhanced rates of goal attainment even when participants already had extremely high scores on relevant motivational variables. For instance, Sheeran \& Orbell (2000) found that if-then planning increased attendance for cervical cancer screening even though the pre-intervention means for intention and self-efficacy among the planning group were 4.60 and 4.63 , respectively, on 1-5 scales. Clearly, it is implausible to attribute the observed $33 \%$ improvement in attendance behavior among implementation intention participants to post-manipulation increases in goal intentions or self-efficacy (see Sheeran \& Orbell, 1999; Verplanken \& Faes, 1999 for equivalent findings). These results, together with findings that show that implementation intention effects do not exhibit the temporal trajectory of motivational interventions (e.g., Sheeran \& Silverman, 2003) and actually show stronger effects for difficult-to-implement goals as compared to easy-to-implement goals (Gollwitzer \& Brandstätter, 1997), indicate that goal intentions and self-efficacy are not the mechanisms by which implementation intentions promote goal achievement.

Gollwitzer (1993, 1999; Gollwitzer \& Schaal, 1998; Gollwitzer \& Sheeran, in press) proposed that two mechanisms that correspond to features of the if- and then-components of the plan explain action control by implementation intentions. Figure 6.1 presents a model delineating the components, mechanisms, and outcomes of implementation intention formation. Forming an if-then plan involves specifying a then-component (an instrumental response or "goal-directed behavior $Z$ ") and an if-component (a viable future opportunity or "situation $Y$ "), and creating mental links between these two components in an if-then format ("If situation $Y$ occurs, then I will initiate goal-directed behavior Z!"). Specifying a good opportunity to act means that the critical situation becomes highly activated and hence more accessible. Enhanced accessibility of the critical situation in turn facilitates subsequent detection of that situation. Forging strong links between the if-component and then-component of the plan, on the other hand, means that the person does not have to deliberate about what to do once the critical situation is encountered. Instead, execution of the goal-directed response follows immediately, efficiently, and without needing conscious intent; responding is automatized.

Empirical studies presented earlier indicate that participants who furnish their goal intentions with respective implementation intentions: (a) exhibit superior detection of specified cues (see Processes related to the if-component), (b) respond swiftly, effortlessly, and without need for conscious intent (see Processes related to the then-component), 


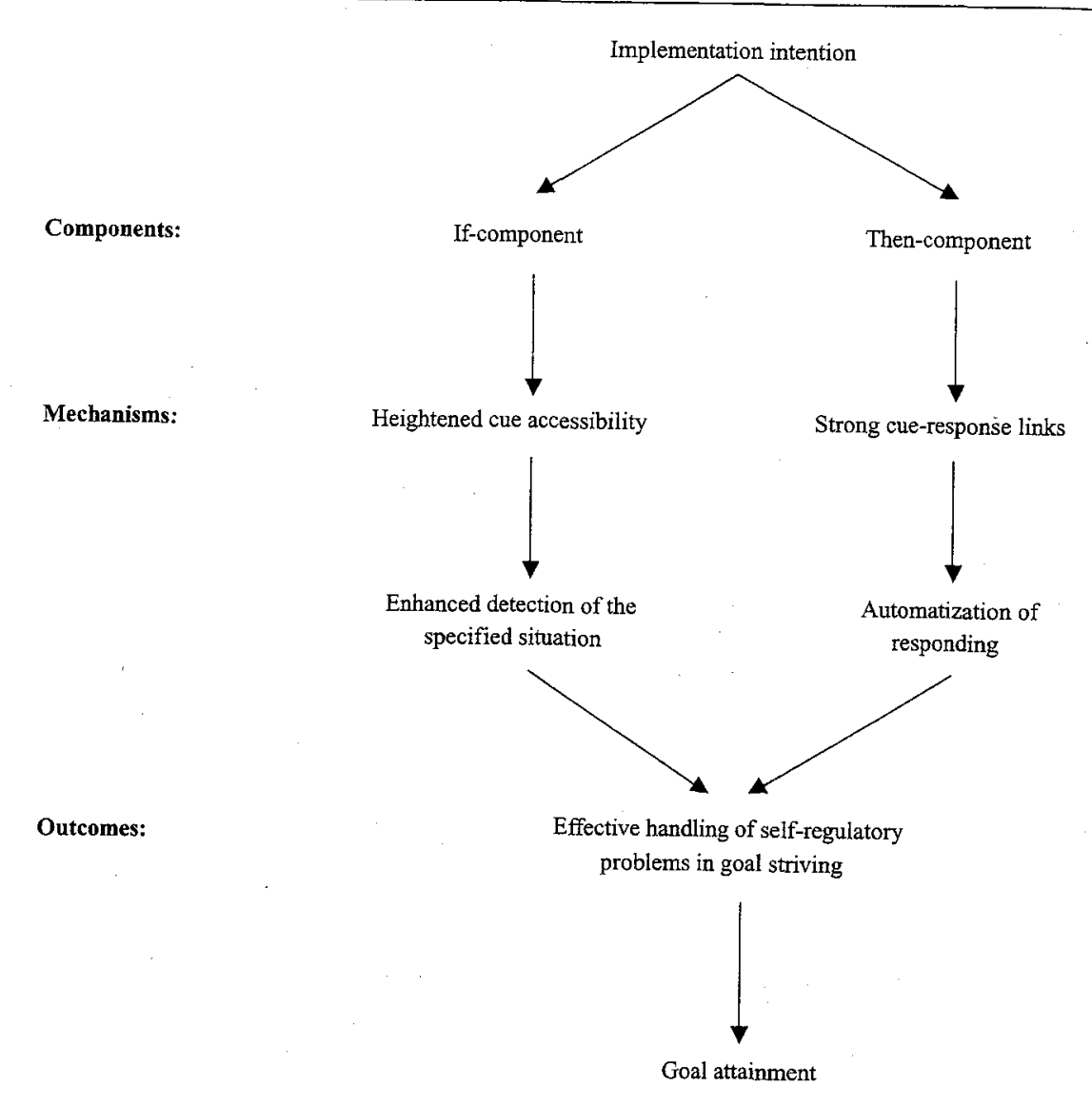

Figure 6.1 Components, mechanisms, and outcomes of implementation intention formation

(c) overcome self-regulatory problems to do with initiating goal striving and shielding ongoing goal pursuit from unwanted influences (see Types of self-regulatory problem) and (d) are likely to achieve their goals (see Implementation intentions and attainment of health goals). However, we have not so far demonstrated that enhanced cue accessibility and strong cue-response links mediate the relationship between implementation intention formation and goal attainment. Recent research by Webb and Sheeran (2005b) provided this evidence.

Participants' goal was to press a key as quickly as possible to indicate whether or not word search puzzles contained words or non-words that they had been shown at the beginning of the experiment (Webb \& Sheeran, 2005b, Experiment 2). One-half of the participants formed an if-then plan to respond to one of the non-words (avenda) especially quickly. The other half of the participants were asked to familiarize themselves with this item in order to speed up their responses (goal intention condition). Prior to undertaking the main puzzle task, participants undertook a lexical decision task that ostensibly was designed to provide a baseline measure of their linguistic ability. In actual fact, the lexical decision task involved a priming procedure that had the following sequence: (a) presentation of a fixation dot for $1,500 \mathrm{~ms}$, (b) presentation of a prime word for $17 \mathrm{~ms}$, (c) presentation of a row of consonants the same length as the prime (postmask) for $225 \mathrm{~ms}$, and (d) presentation of the target word until the participant responded. There were 96 trials, and participants indicated whether each item presented was a word or a nonword.

Among the target and prime items was the cue specified in the implementation intention (avenda) and a word representing the target behavior (press) as well as matched neutral words for the prime and target, and filler words. Accessibility of the critical cue was measured by participants' responses to avenda after priming by neutral cues. The strength of the cue-response link was measured by participants' response latencies to the word press after priming by the critical cue (avenda). Measures of the accessibility of the matched neutral cue, the accessibility of matched neutral behavior, and all other cue-target combinations were also taken.

The main puzzle task was undertaken immediately after the lexical decision task. Participants were presented with a series of $10 \times 10$ matrices of letters that either contained a word from the original memory set, a non-word from the original memory set, or a new word. Participants had to respond as quickly as possible by pressing one of three designated keys. The dependent variable was speed of response to the puzzle containing the non-word avenda.

Findings indicated that implementation intention formation promoted goal attainment. Participants who formed an if-then plan found the avenda item significantly faster than did goal intention participants. Importantly, this improvement in response times did not come at the cost of accuracy, or compromise responses to the other puzzles. Implementation intention participants were just as accurate responding to critical and non-critical puzzle items, and were just as fast in responding to non-critical items, compared to controls.

Findings for cue accessibility and the strength of cue-response links indexed via the lexical decision task also supported predictions. Participants who formed implementation intentions exhibited enhanced accessibility of the critical cue (avenda) compared to goal intention participants; the critical cue was also more accessible than was the matched cue word among participants who planned. Priming of the target behavior by the critical cue also produced faster responses among implementation intention compared to control participants, indicating that the cue-response association (avenda-press) was stronger among participants who planned. The difference between the groups was not significant, however, when the target behavior was primed by the matched neutral cue. The implementation intention and control conditions also did not differ on accessibility of the target behavior, accessibility of the critical cue following priming by the target behavior (response-cue association), or speed of performance in general. Thus, implementation intention formation heightened the accessibility of the critical cue and strengthened the link between the critical cue and the specified response but did not affect the accessibility of other concepts.

Accessibility of the critical cue and the strength of the cue-response link had significant correlations with goal attainment. Increased cue accessibility and stronger associations 
between the critical cue and the target behavior both were associated with faster responses to the avenda puzzle. To test mediation, goal attainment was regressed on cue accessibility, strength of the cue-response link, and condition (implementation intention: formed versus not formed). Findings showed that cue accessibility and strength of the cue-response links remained significant predictors of goal attainment whereas condition was no longer significant. Sobel's (1982) test confirmed that the mediating variables significantly attenuated the relationship between condition and the dependent variable.

These findings support the postulated mechanisms of implementation intention effects. Forming an if-then plan enhances accessibility of the critical situation and forges strong associations between that situation and the goal-directed response. Detection of the specified opportunity to act is facilitated by heightened cue accessibility, whereas strong cue-response links means that the person knows exactly how to act when the opportunity presents itself and so action initiation is automatized. In sum, if-then plans improve the likelihood of goal attainment because the person strategically switches goal striving from a conscious, effortful mode (action control by goal intentions) to a mode involving automatic initiation of behavior by situational cues (action control by implementation intentions)

It is worth noting that Webb and Sheeran's (2005b) findings are consistent with certain accounts of prospective memory (i.e., remembering intentions to perform future actions; reviews by Einstein \& McDaniel, 1996; Ellis \& Kvavilashvili, 2000). McDaniel and Einstein (2000) proposed a multiple-process account of prospective memory that includes both conscious and automatic mechanisms. When the cue is distinctive and there is strong association between the environmental cue and the to-be-remembered intention, then anticipated environmental conditions should automatically trigger recall of the intended action. This analysis of prospective memory parallels Webb and Sheeran's (2005b) test of mediation of implementation intention effects. However, McDaniel and Einstein also posit a second "conscious" mechanism involved in prospective memory. According to this view, people strategically monitor the environment for the presence of the target event and, once this cue is encountered, perform an effortful memory search for the intended response. Such effortful monitoring and retrieval processes seem quite different to action control by implementation intention. For instance, prospective remembering by this route appears to be highly vulnerable to the cognitive demands of an ongoing activity (e.g., Marsh, Hancock \& Hicks, 2002; Smith, 2003) whereas mental load does not compromise the strength of implementation intention effects (e.g., Brandstätter et al., 2001). Further research, and especially mediation analysis, is required on prospective memory processes to determine whether the mechanisms that explain implementation effects--enhanced cue accessibility and strength of cue-response linksmay also explain how intentions are remembered.

\section{DETERMINANTS OF THE STRENGTH OF IMPLEMENTATION INTENTION EFFECTS}

Several factors determine the impact of implementation intention formation on rates of goal achievement. The first concerns the presence of self-regulatory problems. When there are few obstacles to goal achievement, then favorable goal intentions and self-efficacy could suffice in promoting performance, and implementation intention formation might be superfluous (e.g., Gollwitzer \& Brandstätter, 1997; Sheeran \& Orbell, 1999, Study 1). However, when the respective goal striving is difficult, or when people have difficulties pursuing their goals (e.g., schizophrenic patients, opiate addicts; see Brandstätter et al., 2001; Lengfelder \& Gollwitzer, 2001) then it is especially worthwhile to engage in if-then planning (Gollwitzer \& Sheeran, in press).

A second determinant of the strength of implementation intention effects is the state of the respective goal intention. When people have no intention of pursuing a health goal, then they are unlikely to form an implementation intention that spells out adequately when, where, and how the goal will be pursued, even when asked to do so (Sheeran, Milne et al., 2005). Sheeran et al. (2005) showed that strong effects of implementation intentions were obtained only when the underlying goal intention was strong and activated (see also Seehausen, Bayer \& Gollwitzer, 1994, cited in Gollwitzer, 1996). Similarly, Koestner, Lekes, Powers and Chicoine, 2002 showed that if-then plans benefited the completion of personal projects more when those projects were selfconcordant (i.e., consistent with personal interests and values) than when projects were self-discordant (motivated by external reasons such as social pressure). The implication is that intervention studies may need to start out with a motivational initiative to promote requisite goal intentions before having participants complete an implementation intention induction to promote effective translation of their intentions into action.

In addition, several features of the respective if-then plan are important in determining the magnitude of the impact of plan formation on goal attainment. As the model presented in Figure 6.1 suggests, strong implementation intention effects can be anticipated only if the person has: (a) specified a response that is instrumental for completing the goal in the then-component of the plan, (b) specified a viable opportunity to initiate that response in the plan's if-component, and (c) forged strong links between the if-component and then-component of the plan.

The goal-directed behavior specified in an implementation intention needs to be tailored to the self-regulatory problem at hand to promote effective realization of the superordinate goal intention. Three studies that ostensibly are concerned with the same activity, attendance behavior, serve to illustrate the types of response that might prove useful in dealing with particular self-regulatory problems (Sheeran \& Silverman, 2003; Sheeran \& Orbell, 2000; Sheeran, Aubrey \& Kellett, 2005). Sheeran and Silverman (2003) investigated attendance at health and safety training courses among university employees. Evidence indicated that staff generally failed to attend because they found attendance unpleasant, and because they tended to forget relevant details concerning the times and places of different courses. Thus, the self-regulatory problems that prevented attendance had to do with getting started on goal striving. Consequently, the if-then plan was geared towards the initiation of attendance behavior.

Implementation intention and control participants were provided with information about times and locations of six upcoming training courses at the front of the questionnaire. The implementation intention induction came at the end of the questionnaire. Participants were told: "You are more likely to attend a university fire training course in the next three months if you decide now which course you will attend. Using the information provided on the cover, please fill in the following ..." Spaces were provided for participants to write in the time, date, and location of their chosen course. The type of 
then-component specified in the plan is an instigation response (Sheeran, Milne et al., 2005); participants specify which course they will attend. Doing so means that participants come to terms with the immediate affective costs of attending (Trope \& Fishbach, 2005). Moreover, if-then planning heightens the accessibility of the chosen time and date thereby making it less likely that attendance will be forgotten. Spelling out the goal-directed response in this way appeared to be highly. effective in dealing with the problem of getting started. Objective records indicated if-then plans doubled the rate of attendance at health and safety training courses (35\% versus $14 \%$ ).

The same self-regulatory problems to do with forgetting to act and dealing with initial reluctance also explain non-attendance for cervical cancer screening (review by Orbell \& Sheeran, 1993). However, it was not feasible simply to ask participants to specify when and where they would attend in this study (Sheeran \& Orbell, 2000). This is because all participants received an invitation letter that merely informed them that they should obtain screening within the next three months. In order to be screened, the women had to contact their General Practitioner to arrange a suitable appointment. Thus, it was necessary to perform a behavior in the service of goal attainment (i.e., make an appointment) to achieve the desired outcome (i.e., screening attendance). The thencomponent of the implementation intention therefore specified instigation of the behavioral means of achieving the goal (rather than the goal per se).

Implementation intention participants received the following passage at the end of a questionnaire concerning their views about cervical cancer screening: "You are more likely to go for a cervical smear if you decide when and where you will go. Please write in below when, where, and how you will make an appointment." Participants wrote their answers under each of three headings using the spaces provided. Specifying the instigation of the behavioral means of achieving the goal appears to have been highly effective in promoting goal attainment. Medical records indicated that, whereas only $69 \%$ of the control group subsequently attended for screening, $92 \%$ of participants who formed implementation intentions did so. Post hoc analyses indicated that making an appointment was an effectual means of ensuring attendance $-100 \%$ of participants who made an appointment subsequently attended for cervical cancer screening. This finding underlines the role of instrumentality of the goal-directed response in determining the strength of implementation intention effects.

The final attendance behavior concerned appointments for psychotherapy (Sheeran, Aubrey \& Kellett, 2005). Here, the relevant self-regulatory problem has less to do with the initiation of goal striving than with shielding goal striving from unwanted influences during the lengthy interval between seeking help and obtaining treatment. There are long waiting lists for psychotherapy in the UK, and people generally wait at least 6 months to see a clinical psychologist or psychotherapist. During this time, people are likely to have to deal with a variety of negative thoughts and feelings that could undermine attendance for psychotherapy. For instance, people may ruminate about the self-evaluative implications of seeking psychological help, or they may feel ashamed, embarrassed, or stigmatized about needing therapy. Not surprisingly, therefore, $30-60 \%$ of people who are offered psychotherapy fail to attend their appointment (Hughes, 1995).

The then-component specified in this study was therefore geared at dealing effectively with unwanted influences that might derail goal striving, and in particular, negative affective experiences that could prevent attendance. The goal-directed behavior involved the suppression of responses that could hinder goal attainment. The following implementation intention induction was included at the end of a questionnaire concerning perceptions of therapy:

People can sometimes feel concerned about attending their appointment. To help you manage these concerns, please read the statement below 3 times and then repeat the statement silently to yourself one more time:

As soon as I feel concerned about attending my appointment, I will ignore that feeling and tell myself this is perfectly understandable!

Now please tick the box below if you have read the statement three times and said it to yourself once (please be honest; do not tick the box until you have read and repeated the statement)

Implementation intention formation again proved effective in promoting attendance behavior. Whereas only $57 \%$ of control participants attended their psychotherapy appointment, $83 \%$ of participants who formed an if-then plan did so. These findings demonstrate the importance of: (a) identifying the key self-regulatory problems that undermine people's ability to translate a focal intention into action, and (b) specifying a response that is effective in dealing with these self-regulatory problems in the thencomponent of the implementation intention. Implementation intentions can be targeted at instigating a response that leads to goal attainment or at suppressing a response that prevents goal attainment. Clearly, in order to observe the greatest benefits for goal completion, it is important to specify the response that has the greatest instrumentality with respect to reaching the goal.

Gollwitzer and Sheeran (in press) pointed out that features of the if-then component of the plan also can have an important influence on the extent to which implementation intention formation promotes goal achievement. In particular, the specified opportunity needs to be both viable and precise to obtain strong implementation intention effects. For instance, if the specified situation is not viable (e.g., because the situation hardly ever arises, or presents urgent competing goals) then goal-directed behavior might never be initiated. Similarly, if the critical situation is spelled out only vaguely in the plan (e.g., "next week"), then the person may fail to detect relevant cues or may have to deliberate in situ about whether or not this is a good time to act. As a result, crucial chances to pursue the goal might be missed. Of course, the opportunities specified in the ifcomponent of the plan can refer either to environmental circumstances (e.g., a particular time and place) or internal states (e.g., feelings of concern about attending for psychotherapy). The issue of precision is not to do with specifying internal versus external cues, but rather whether the person is forced to reflect on whether the critical situation has arrived. In the same way that implementation intentions benefit rates of goal attainment because the person does not have to deliberate in situ about action to perform (because the action was specified in advance in the then-component of the plan), the person also should not need to deliberate in situ about when and where to act.

The final feature of implementation intention formation that is important in determining how much planning benefits goal attainment concerns the strength of the association between the if-component and then-component of the plan (cue-response linkage). Webb 
and Sheeran's (2005b) findings indicate that strong links between the specified opportunity and goal-directed behavior mediate the relationship between if-then planning and action initiation. However, this analysis also implies that procedures that serve to strengthen or weaken cue-response associations should fortify or attenuate implementation intention effects, respectively. For instance, if participants pay little attention to the link between the cue and response during implementation intention formation then modest implementation intention effects would be anticipated. Conversely, instructing participants to concentrate on this link should enhance the impact of the plan. Consistent with this idea, Milne and Sheeran (2002b) found that participants who rehearsed the link between their specified opportunity and specified action were much more likely to visit a target website than were participants who specified these components on a reminder note and put it in a prominent place at home (rates were $87 \%$ versus $40 \%$, respectively). In sum, the presence of a self-regulatory problem, the state (activation, strength) of the underlying goal intention and features of the plan (instrumentality of the response, viability and precision of the opportunity, cue-response linkage) all are important determinants of the strength of implementation intention effects.

\section{CONCLUSION}

Models of health behavior predominantly are concerned with the factors that determine strong goal intentions. However, accumulated evidence indicates that people often fail to convert even strong goal intentions into successful attainment of health goals. This is because of self-regulatory problems to do with initiating goal striving or shielding an ongoing goal pursuit from unwanted influences which undermine goal progress. Forming implementation intentions in the service of goal intentions engenders strategic automatization of goal striving and thus helps people to deal effectively with these selfregulatory problems. The consequence is that if-then plan formation enhances rates of attainment of health goals compared to the formation of a goal intention on its own.

Although progress in implementation intention research has been substantial, there is considerable scope for further research. For instance, relatively few studies have examined the control of unwanted, health-risk behaviors (e.g., smoking, over-eating), and further tests are warranted. Comparisons of the effectiveness of different goaldirected responses (e.g., instigation versus ignore responses) in dealing with particular self-regulatory problems would be valuable, as would tests of the utility of combining these different goal-directed responses. Characteristics of implementation intention inductions that ensure optimal specification of opportunities and responses in people's plans, and optimize the strength of cue-response links also deserve rigorous analysis. Finally, people typically hold manifold, complex health goals (e.g., to eat a low-fat diet and avoid smoking) and future studies will need to assess to what extent people benefit from forming multiple implementation intentions (with respect to both one or more different behaviors). Provided that there is no conflict between the opportunities and responses specified in respective if-then plans, then implementation intention formation should promote the attainment of both complex and various goals. However, these are all empirical issues that can, and should be, tested by health psychologists in future research.

\section{REFERENCES}

Aarts, H. \& Dijksterhuis, A. (2000a). Habits as knowledge structures: Automaticity in goai-directed behavior. Joumal of Personality and Social Psychology, 78, 53-63.

Aarts, H. \& Dijksterhuis, A. (2000b). On the automatic activation of goal-directed behavior: The case of travel habit. Journal of Environmental Psychology, 20, 75-82.

Aarts, H., Dijksterhuis, A. \& Midden, C. (1999). To plan or not to plan? Goal achievement or interrupting the performance of mundane behaviors. European Joumal of Social Psychology, 29 , 971-979.

Ajzen, I. (1991). The theory of planned behavior. Organizational Behavior and Human Decision Processes, 50, 179-211.

Armitage, C.J. (2004). Impiementation intentions and eating a low-fat diet: A randomized controlled trial. Health Psychology, 23, 319-323.

Bandura, A. (1997). Self-efficacy: The exercise of control. New York: W.H. Freeman.

Bargh, J.A. (1994). The four horsemen of automaticity: Awareness, efficiency, intention, and control in social interaction. In R.S. Wyer, Jr. \& T.K. Srull (Eds), Handbook of Social Cognition (2nd edn, pp. 1-40). Hillsdale, NJ: Erlbaum.

Bayer, U.C., Moskowitz, G.B. \& Gollwitzer, P.M. (2002). Implementation Intentions and Action Initiation Without Conscious Intent. Unpublished manuscript, University of Konstanz, Germany.

Brandstätter, V., Lengfelder, A. \& Gollwitzer, P.M. (2001). Implementation intentions and efficient action initiation. Journal of Personality and Social Psychology, 81, 946-960.

Bryan, A., Fisher, J.D. \& Fisher, W.A. (2002). Tests of the mediational role of preparatory safer sexual behavior in the context of the theory of planned behavior. Health Psychology, 21 $71-80$.

Brüwer, J., Bayer, U.C. \& Gollwitzer, P.M. (2002, July). Intentional Control of the Simon Effect. Poster presented at the International Conference on Executive Functions, Konstanz, Germany.

Carver, C.S. \& Scheier, M.F. (1982). Control theory: A useful conceptual framework for personalitysocial, clinical, and health psychology. Psychological Bulletin, 92, 111-135.

Cohen, J. (1992). A power primer. Psychological Bulletin, 112, 155-159.

Einstein, G.O. \& McDaniel, M.A. (1996). Retrieval processes in prospective memory: Theoretical approaches and some new empirical findings. In M. Bradimonte, G.O. Einstein \& M.A. McDaniel (Eds), Prospective Memory: Theory and applications. Mahwah, NJ: Erlbaum.

Einstein, G.O., McDaniel, M.A., Williford, C.L., Pagan, J.L. \& Dismukes, R.K. (2003). Forgetting of intentions in demanding situations is rapid. Joumal of Experimental Psychology: Applied, 9, $147-162$.

Ellis, J. \& Kvavilashvili, L. (2000). Prospective memory in 2000: Past, present, and future directions. Applied Cognitive Psychology, 14 (Suppl.), 1-9.

Fife-Schaw, C., Sheeran, P. \& Norman, P. (in press). Simulating Behaviour Change Interventions Based on the Theory of Planned Behaviour: Impacts on intentions and behaviour. British Journal of Social Psychology.

Gibbons, F.X., Gerrard, M., Blanton, H. \& Russell, D.W. (1998). Reasoned action and social reaction: Willingness and intention as independent predictors of health risk. Journal of Personality and Social Psychology, 74, 1164-1180.

Gollwitzer, P.M. (1990). Action phases and mindsets. In E.T. Higgins \& J.R.M. Sorrentino (Eds), The Handbook of Motivation and Cognition (Vol. 2, pp. 53-92). New York: Guilford.

Gollwitzer, P.M. (1993). Goal achievement: The role of intentions. In W. Stroebe \& M. Hewstone (Eds), European Review of Social Psychology (Vol. 4, pp. 141-185). Chichester: John Wiley \& Sons, Ltd. 
Gollwitzer, P.M. (1996). The volitional benefits of planning. In P.M. Gollwitzer \& J.A. Bargh (Eds) The Psychology of Action: Linking cognition and motivation to behavior (pp. 287-312). New York: Guilford.

Gollwitzer, P.M. (1999). Implementation intentions: Strong effects of simple plans. American Psychologist, 54, 493-503.

Gollwitzer, P.M., Achtziger, A., Schaal, B. \& Hammelbeck, J.P. (2002). Intentional Control of Stereotypical Beliefs and Prejudicial Feelings. Unpublished manuscript, University of Konstanz, Germany.

Gollwitzer, P.M., Bayer, U.C. \& McCulloch, K.C. (2005). The control of the unwanted. In R.R. Hassin, J.S. Uleman \& J.A. Bargh (Eds), The New Unconscious (pp. 485-515). New York: Oxford University Press.

Gollwitzer, P.M., Bayer, U.C., Steller, B. \& Bargh, J.A. (2002). Delegating Control to the Environment: Perception, attention, and memory for pre-selected behavioral cues. Unpublished manuscript, University of Konstanz, Germany.

Gollwitzer, P.M. \& Brandstätter, V. (1997). Implementation intentions and effective goal pursuit. Journal of Personality and Social Psychology, 73, 186-199.

Gollwitzer, P.M., Jaudas, A., Parks, E. \& Sheeran, P. (in press). Flexibility tenacity in goal pursuit. In J. Shah \& W. Gardner (Eds), Handbook of Motivation Science. New York: Guilford.

Gollwitzer, P.M. \& Schaal, B. (1998). Metacognition in action: The importance of implementation intentions. Personality and Social Psychology Review, 2, 124-136.

Gollwitzer, P.M. \& Sheeran, P. (in press). Implementation intentions and goal achievement: A metaanalysis of effects and processes. Advances in Experimental Social Psychology.

Gollwitzer, P.M., Sheeran, P., Trötschel, R. \& Webb, T.L. (2005). The Control of Behavior Priming Effects by Implementation Intentions. Manuscript submitted for publication.

Gottschaldt, K. (1926). Über den Einflu $\beta$ der Erfahrung auf die Wahrnehmung von Figuren (On the effects of familiarity on the perception of figures). Psychologische Forschung, 8 261-317.

Higgins, A. \& Conner, M. (2004). Preventing Adolescent Smoking Using Implementation Intentions. Manuscript submitted for publication.

Hughes, I. (1995). Why do they stop coming? Reasons for therapy termination by adult clinical psychology clients. Clinical Psychology Forum, 81, 7-12.

Jones, F., Abraham, C., Harris, P., Schulz, J. \& Chrispin, C. (2001). From knowledge to action regulation: Modeling the cognitive prerequisites of sun screen use in Australian and UK samples. Psychology and Health, 16, 191-206.

Koestner, R., Lekes, N., Powers, T.A. \& Chicoine, E. (2002). Attaining personal goals: Selfconcordance plus implementation intentions equals success. Journal of Personality and Social Psychology, 83, 231-244.

Lengfelder, A. \& Gollwitzer, P.M. (2001). Reflective and reflexive action control in patients with frontal brain lesions. Neuropsychology, 15, 80-100.

Leventhal, H., Singer, R. \& Jones, S. (1965). Effects of fear and specificity of recommendation upon attitudes and behaviour. Journal of Personality and Social Psychology, 2, 20-29.

Leventhal, H., Watts, J.C., Pagano, F. (1967). Effects of fear and instructions on how to cope with danger. Journal of Personality and Social Psychology, 6, 313-321.

Lippke, S. \& Ziegelmann, J.P. (2002). Self-regulation and exercise: A Study on Stages of Change and Successful Ageing. Unpublished manuscript, Free University of Berlin, Germany.

Marsh, R.L., Hancock, T.W. \& Hicks, J.L. (2002). The demands of an ongoing activity influence the success of event-based prospective memory. Psychonomic Bulletin and Review, 9, 604-610.

Marsh, R.L., Hicks, J.L. \& Watson, V. (2002). The dynamics of intention retrieval and coordination of action in event-based prospective memory. Journal of Experimental Psychology: Learning. Memory, and Cognition, 28, 652-659.
McCaul, K.D., Glasgow, R.E. \& O'Neill, H.K. (1992). The problem of creating habits: Establishing health-protective dental behaviors. Health Psychology, 11, 101-110.

McDaniel, M.A. \& Einstein, G.O. (2000). Strategic and automatic processes in prospective memory retrieval: A multiprocess framework. Applied Cognitive Psychology, 14, S127S144.

Milne, S., Orbell, S. \& Sheeran, P. (2002). Combining motivational and volitional interventions to promote exercise participation: Protection motivation theory and implementation intentions. British Journal of Health Psychology, 7, 163-184.

Milne, S. \& Sheeran, P. (2002a, June). Combining motivational and volitional interventions to prevent testicular cancer. Paper presented to the 13th General Meeting of the European Association of Experimental Social Psychology, San Sebastian, Spain.

Milne, S. \& Sheeran, P. (2002b, October). Making Good Implementation Intentions: Comparing Associative Learning and Prospective Memory in Remembering Intentions. Paper presented to the 16th Conference of the European Health Psychology Society, Lisbon, Portugal.

Murgraff, V., White, D. \& Phillips, K. (1996). Moderating binge drinking: It is possible to change behaviour if you plan it in advance. Alcohol and Alcoholism, 6, 577-582.

Oettingen, G., Hönig, G. \& Gollwitzer, P.M. (2002). Effective self-regulation of goal attainment. International Journal of Educational Research, 33, 705-732.

Oettingen, G. \& Gollwitzer, P.M. (2001). Goal setting and goal striving. In A. Tesser \& N. Schwarz (Eds), Intraindividual Processes (Volume 1 of the Blackwell Handbook in Social Psychology, pp. 329-347). Oxford, UK: Blackwell.

Orbell, S., Hodgkins, S. \& Sheeran, P. (1997). Implementation intentions and the theory of planned behavior. Personality and Social Psychology Bulletin, 23, 945-954.

Orbell, S. \& Sheeran, P. (1993). Health Psychology and the uptake of preventive health services: A review of thirty years' research on cervical screening. Psychology and Health, 8, 417-433.

Orbell, S. \& Sheeran, P. (1998). 'Inclined abstainers': A problem for predicting health-related behavior. British Journal of Social Psychology, 37, 151-165.

Orbell, S. \& Sheeran, P. (1999). Volitional Strategies and the Theory of Planned Behavior. Unpublished manuscript, University of Sheffield, UK.

Orbell, S. \& Sheeran, P. (2000). Motivational and volitional processes in action initiation: A field study of the role of implementation intentions. Journal of Applied Social Psychology, 30, 780797.

Ouellette, J.A. \& Wood, W. (1998). Habit and intention in everyday life: The multiple processes by which past behavior predicts future behavior. Psychological Bulletin, 124, 54-74.

Prestwich, A., Lawton, R. \& Conner, M. (2003a). Use of implementation intentions and the decision balance sheet in promoting exercise behaviour. Psychology and Health, 18, 707-721.

Prestwich, A. Lawton, R. \& Conner, M. (2003b). Increasing the Impact of Implementation Intentions: The impact of environmental cues, rehearsal and sufficient plans. Unpublished manuscript, University of Leeds, UK.

Rise, J., Thompson, M. \& Verplanken, B. (2003). Measuring implementation intentions in the context of the theory of planned behavior. Scandinavian Journal of Psychology, 44, 87-95.

Rogers, R.W. (1983). Cognitive and physiological processes in fear appeals and attitude change: a revised theory of protection motivation. In B.L. Cacioppo \& L.L. Petty (Eds), Social Psychophysiology: A sourcebook (pp. 153-176). London: Guildford.

Schwarzer, R. (1992). Self-efficacy in the adoption and maintenance of health behaviours: Theoretical approaches and a new model. In R. Schwarzer (Ed.), Self-efficacy: Thought control of action. Washington, DC: Hemisphere.

Schweiger Gallo, I., McCuiloch, K.C. \& Gollwitzer, P.M. (2005, January). “Don't Get So Emotional!" Volitional Control of Emotions Via Implementation Intentions. Poster presented at the Society for Personality and Social Psychology Annual Meeting, New Orleans, Louisiana. 
Sheeran, P. (2002). Intention-behavior relations: A conceptual and empirical review. In W. Stroebe \& M. Hewstone (Eds), European Review of Social Psychology (Vol. 12., pp. 1-30). Chichester: John Wiley \& Sons, Ltd.

Sheeran, P. (2004). Unpublished raw data, University of Sheffield, UK

Sheeran, P., Aarts, H., Custers, R., Rivis, A., Webb, T.L. \& Cooke, R. (2005). The goal-dependent automaticity of drinking habits. British Journal of Social Psychology, 44, 47-64.

Sheeran, P., Abraham, C. \& Orbell, S. (1999). Psychosocial correlates of heterosexual condom use: A meta-analysis. Psychological Bulletin, 125, 90-132.

Sheeran, P. \& Armitage, C.J. (2003). Unpublished raw data, University of Sheffield, UK.

Sheeran, P., Aubrey, R. \& Kellett, S. (2003). Unpublished raw data, University of Sheffield, UK Sheeran, P. \& Milne, S. (2003). Unpublished raw data, University of Sheffield, UK.

Sheeran, P., Milne, S.E., Webb, T.L. \& Gollwitzer, P.M. (2005). Implementation intentions. In M. Conner \& P. Norman (Eds), Predicting Health Behaviour (pp. 276-323). Buckingham, UK: Open University Press.

Sheeran, P. \& Orbell, S. (1998). Do intentions predict condom use? A meta-analysis and examination of six moderator variables. British Journal of Social Psychology, 37, 231-250.

Sheeran, P. \& Orbell, S. (1999). Implementation intentions and repeated behavior: Augmenting the predictive validity of the theory of planned behavior. European Joumal of Social Psychology, 29 349-369.

Sheeran, P. \& Orbell, S. (2000). Using implementation intentions to increase attendance for cervical cancer screening. Health Psychology, 19, 283-289.

Sheeran, P. \& Silverman, M. (2003). Evaluation of three interventions to promote workplace health and safety: Evidence for the utility of implementation intentions. Social Science and Medicine, 56, 2153-2163

Sheeran, P., Webb, T.L. \& Gollwitzer, P.M. (2005). The interplay between goal intentions and implementation intentions. Personality and Social Psychology Bulletin, 31, 87-98.

Smith, R.E. (2003). The cost of remembering to remember in event-based prospective memory: Investigating the capacity demands of delayed intention performance. Journal of Experimental Psychology: Learning, Memory, and Cognition, 29, 347-361.

Sniehotta, F.F., Scholtz, U. \& Schwarzer, R. (2002a). The Effects of Planning on Initiation and Maintenance of Physical Activity in Cardiac Rehabilitation Patients. Unpublished manuscript, Free University, Berlin, Germany.

Sniehotta, F.F., Scholtz, U. \& Schwarzer, R. (2002b). Implementation Intentions and Coping Intentions. Unpublished manuscript, Free University, Berlin, Germany.

Steadman, L. \& Quine, L. (2000). Are Implementation Intentions Useful for Bridging the Intentionbehavior Gap in Adhering to Long-term Medication Regimens? An Attempt to Replicate Sheeran and Orbell's (1999) Intervention to Enhance Adherence to Daily Vitamin C Intake. Paper presented to the British Psychological Society Division of. Health Psychology Annual Conference, University of Kent at Canterbury, UK.

Steadman, L. \& Quine, L. (2004). Encouraging males to perform testicular self-examination: A simple, but effective, implementation intention intervention. British Journal of Health Psychology, 9, 479-487.

Stephens, A. \& Conner, M. (1999, September). A Smoking Prevention Intervention in Adolescents. Paper presented at the British Psychological Society Division of Health Psychology Annual Conference, University of Leeds, UK.

Triandis, H.C. (1980). Values, attitudes, and interpersonal behavior. In H. Howe \& M. Page (Eds), Nebraska Symposium on Motivation (Vol. 27, pp. 195-259). Lincoln, NE: University of Nebraska Press.
Trope, Y. \& Fishbach, Y. (2005). Going beyond the motivation given: Self-control and situationa control over behavior. In R.R. Hassin, J.S. Uleman \& J.A. Bargh (Eds), The New Unconscious (pp. 537-566). New York: Oxford University Press.

Verplanken, B. \& Faes, S. (1999). Good intentions, bad habits, and effects of forming implementation intentions on healthy eating. European Journal of Social Psychology, 29, 591-604.

Webb, T.L. \& Sheeran, P. (2004). Identifying good opportunities to act: Implementation intentions and cue discrimination. European Journal of Social Psychology, 34, 407-419.

Webb, T.L: \& Sheeran, P. (2005a). Integrating concepts from goal theories to understand the achievement of personal goals. European Journal of Social Psychology, 35, 69-96.

Webb, T.L. \& Sheeran, P. (in press). Does Changing Behavioral Intentions Engender Behavior Change? A Meta-analysis of the Experimental Evidence. Psychologica Bulletin.

Webb, T.L. \& Sheeran, P. (2005b). How Do Implementation Intentions Promote Goal Attainment? Tests of Component Processes. Manuscript submitted for publication.

Webb, T.L., Sheeran, P. \& Luszczynska, A. (2005). Unpublished raw data, University of Sheffeld, UK.

Wood, W., Quinn, J.M. \& Kashy, D. (2002). Habits in everyday life: The thought and feel of action Journal of Personality and Social Psychology, 83, 1281-1297. 